\title{
Antigenic Relationships of Murine Coronaviruses
}

\author{
By \\ J. C. Childs ${ }^{1}$ *, S. A. Stohlman ${ }^{2}$, I. Kingsford 1 , and R. Russell ${ }^{1}$ \\ 1. The Department of Microbiology, California State University, \\ Long Beach, California, U.S.A., and the \\ 2 Department of Neurology and Microbiology, \\ The University of Southern California, School of Medicine, \\ Los Angeles, California, U.S.A. \\ With 1 Figure \\ Accepted June 10, 1983
}

\begin{abstract}
Summary
Two serological tests were used to examine the antigenic relationships between murine hepatitis viruses that cause different diseases in mice. Antisera prepared by immunization of mice with the individual viruses were tested for their ability to neutralize both the homologous immunogen and the other viruses. By a plaque reduction neutralization test, each antiserum was found to be specific for the immunizing virus; however, there was substantial cross-reactivity, indicating the viruses were closely related. By kinetic neutralization, two of the viruses tested, MHV.JHM and MHV-2, were found to be antigenically distinct. MHV-3 and MHV.A59 were found to be antigenically very similar but distinct. These data show that kinetic neutralization is a more precise method for determining the antigenic relationships between murine coronaviruses.
\end{abstract}

\section{Introduction}

Mouse hepatitis viruses (MHV) are members of the coronavirus group of enveloped, positive-stranded RNA viruses $(6,10)$. MHV particles are basically composed of three proteins, a major envelope glycoprotein ( $\mathrm{gp} 90 / 180$ ), a minor envelope glycoprotein ( $\mathrm{gp} 25$ ), and a phosphorylated nucleocapsid protein ( $\mathrm{pp}$ 60) (10). In general, MHV infection results in a persistent infection in the gastrointestinal tract of mice $(2,16)$. The viruses become clinically apparent following a variety of stressful conditions, and as a group, produce a spectrum of diseases in which many organs are infected and affected. Although most isolates of MHV exhibit some degree of hepatotropism, the individual members exhibit various

* Present address: Department of Pathology S 502, University of Arkansas Medical Sciences Campus, Little Rock, Arkansas, U.S.A.

6 Arch. Virol. $78 / 1-2$ 
amounts of organ tropism. Hepatitis may be the primary disease produced by some isolates; however, hepatitis can also be secondary to encephalomyelitis, enteritis, or the so called “wasting disease" (16). In addition, all MHV's analyzed have extremely variable pathogenicities depending upon the age and genetic background of the host. For example, the neurotropic strain, MHV-JHM, is lethal for 6 week old C57 BL/6 and SJL mice, but it is nonpathogenic for 12 week old SJL $(10,11)$.

MHV's are used as models for a variety of disease processes, and it has become increasingly clear that the distinction between the strains based upon their designation at the time of isolation needs critical evaluation. Plaque reduction neutralization has been used to address the question of antigenic relationships among various MHV isolates. Although these data have indicated several relationships among the MHV's, our data confirm that comparison of the members of this virus group by plaque reduction neutralization does not clearly separate the various strains $(3,14,15)$.

\section{Materials and Methods}

\section{Cells and Viruses}

The propagation and plaque assay of all MHV strains used in this study were carried out on DBT monolayers as previously described $(4,7)$. The derivation and passage history of MHV strains MHV-JHM and MHV-A59 were previously deseribed $(6,7)$. The MHV -2 strain was kindly provided by Dr. K. Fujiwara, Tokyo, Japan. All other MHV strains were kindly provided by Dr. M. Collins, Microbiological Associates, Bethesda, MD. Each isolate was plaque purified at least 3 times on DBT cells before use.

\section{Neutralization Tests}

Virus pelleted by centrifugation of clarified tissue culture medium at $56,000 \times g$ for 3 hours was used as the immunogen. Antisera were prepared for each virus by multiple injections of $\mathrm{C} 57 \mathrm{BL} / 6$ mice ( $4-6$ mice per group) using a schedule previously described (11). Sarcoma 180 cells were used to induce ascites in the immunized mice and the aseitic fluid was used as the source of antiviral antibody. Ascitic fluids from the individual mice were pooled prior to testing.

The ability of each antiserum to neutralize homologous and heterologous viruses was first tested by a plaque-reduction neutralization method. Briefly, sequential twofold dilutions of heat-ine ctivated antisera $\left(56^{\circ} \mathrm{C}\right.$ for 30 minutes) were mixed with an equal quantity of virus calculated to yield $30-60 \mathrm{PFU} /$ plate in $0.1 \mathrm{ml}$. After one hour at $37^{\circ} \mathrm{C}$ the residual plaques were determined by plaque assay. The reciprocal of the antibody dilution which reduced the number of plaques by 50 per cent was determined from a log probit plot and designated as the titer. Four viruses were tested by kinetic neutralization. In this test, approximately $2 \times 10^{6} \mathrm{PFU}$ were mixed with an equal quantity of antiserum or fetal calf serum, and the residual virus determined as a function of time at $37^{\circ} \mathrm{C}$.

\section{Results}

\section{Plaque Reduction Test}

In an attempt to understand not only the antigenic relationships among the various MHV strains, but to also determine if any members were antigenically distinct, antiserum was prepared against each isolate and the cross reactivity tested by plaque-reduction. The MHV isolates examined included a relatively 
nonpathogenic strain (MHV-A59), four hepatotropic strains (MHV-1, MHV-2, MHV-3, MHV-S), and a neurotropic strain which causes minimal liver disease (MHV-JHM). Table 1 shows the titers obtained when the antisera prepared by immunization with the individual viruses were tested for their ability to neutralize the homologous immunogen and the heterologous viruses. Each of the antisera tested was most reactive with its homologous immunogen, indicating by this criterion that each of these viruses had unique antigenic determinants. However, there was significant cross reactivity, defined as less than a four-fold difference, between the homologous virus-antibody titer and a number of the heterologous virus-antibody titers. The only exception was the antiserum against MHV-JHM. This indicated that the major envelope glycoprotein, which accounts for the neutralization of MHV, was antigenically distinct.

\section{Kinetic Neutralization Tests}

Four of these viruses were examined by kinetic neutralization to more clearly define the serological differences between the MHV isolates. Initially, the antiserum produced against the MHV-JHM was tested for its ability to neutralize all four strains in a kinetic type neutralization. This serum was tested first because of its limited cross-reactivity by plaque reduction neutralization. Fig. 1 a shows that anti-MHV-JHM serum neutralized the MHV-JHM more rapidly than any of the three other viruses tested. By the kinetic test, the heterologous viruses were all neutralized to some extent by the MHV-JHM antiserum, but no conclusive interrelationships could be distinguished. Each virus strain was tested after 90 minutes at $37^{\circ} \mathrm{C}$ for thermal degradation and no significant heat inactivation occurred.

Fig. $1 \mathrm{~b}$ demonstrates that the antiserum prepared against MHV-2 clearly distinguished the homologous virus from the other three MHV strains tested. Interestingly, there was no significant neutralization of the other three strains by this serum in the kinetic test although plaque reductions indicated a high level of cross-reactivity with MHV-3 and MHV-A59 (Table 1).

Table 1. Antigenic Relationships of MHV Strains by Plaque Neutralization Test

\begin{tabular}{|c|c|c|c|c|c|c|}
\hline \multirow[b]{2}{*}{ Virus } & \multicolumn{6}{|c|}{ Immune Ascites Fluid } \\
\hline & $\begin{array}{l}\text { MHV- } \\
\text { JHM }\end{array}$ & MHV-1 & MHV-2 & MHV-3 & $\begin{array}{l}\text { MHV- } \\
\text { A 59 }\end{array}$ & Control $b$ \\
\hline MHV-JHM & $\mathbf{1}, \mathbf{0 5 0 ^ { \mathrm { a } }}$ & 225 & 62 & 560 & 180 & 4 \\
\hline MHV-1 & 82 & 7,600 & 7,750 & 1,640 & 3,300 & 2 \\
\hline MHV-2 & 72 & 3,500 & 16,500 & 2,300 & 459 & 8 \\
\hline MHV.3 & 63 & 1,200 & 8,000 & 7,300 & 1,050 & 2 \\
\hline MHV-A 59 & 93 & 2,050 & 9,400 & 5,600 & 3,775 & 2 \\
\hline MHV-S & 150 & 4,500 & 8,850 & 2,660 & 2,600 & 4 \\
\hline
\end{tabular}

a Neutralizing antibody titers expressed as the reciprocal of the dilution inhibiting 50 percent of the input virus. The homologous titers are underlined.

b Neutralizing titer of normal serum. 


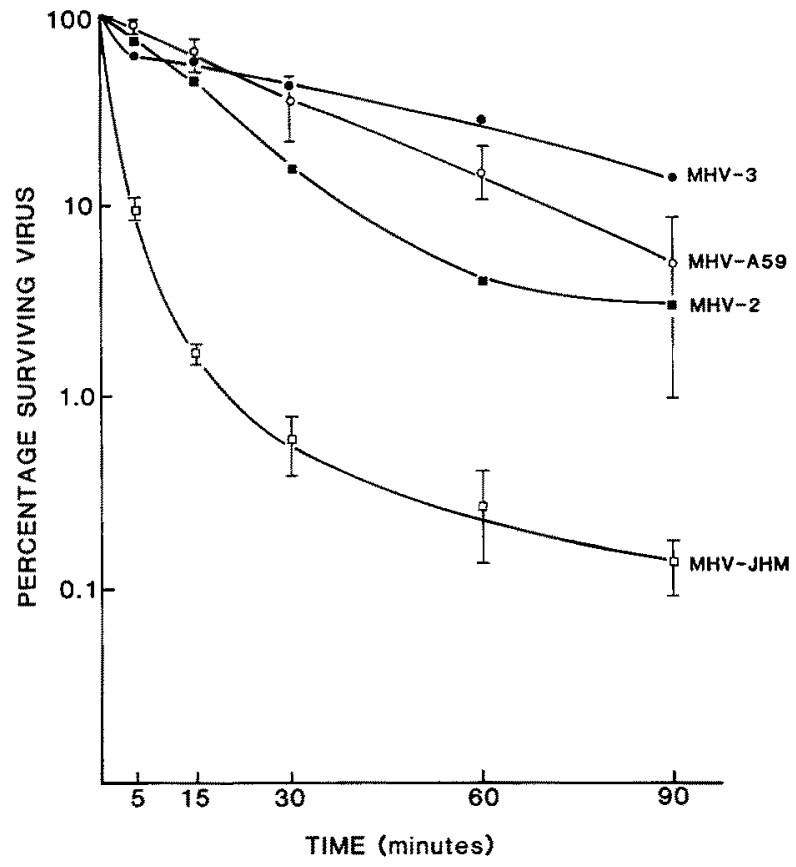

Fig. 1 a

Fig. 1. Kinetic neutralization of MHV.JHM (口), MHV.2 (•), MHV-3 (•), and MHV. A59 (o), by antibody raised by immunization with MHV-JHM (a), MHV-2 (b), MHV-3 (c), and MHV-A59 (d)

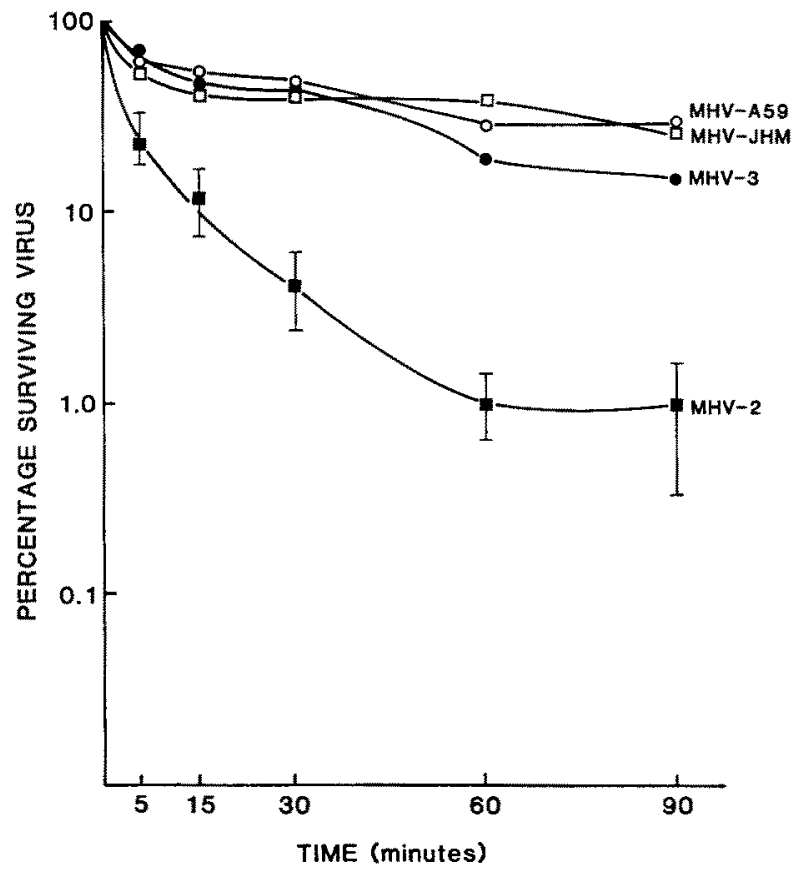

Fig. $1 \mathrm{~b}$ 
Antigenic Relationships of $\mathrm{MHV}$

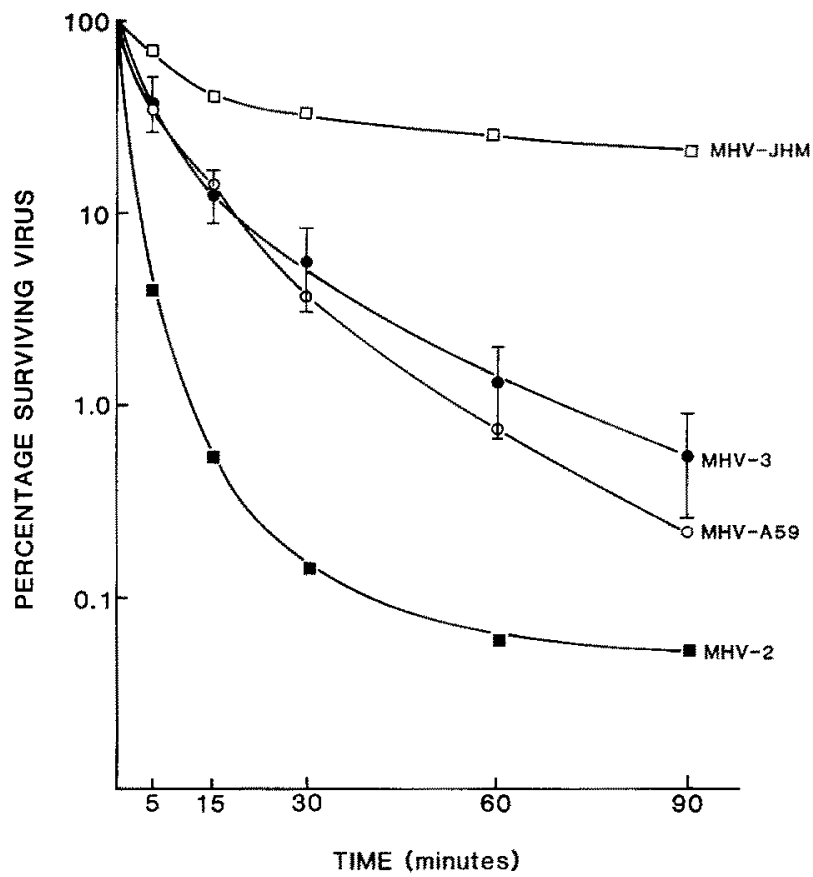

Fig. $1 \mathrm{c}$

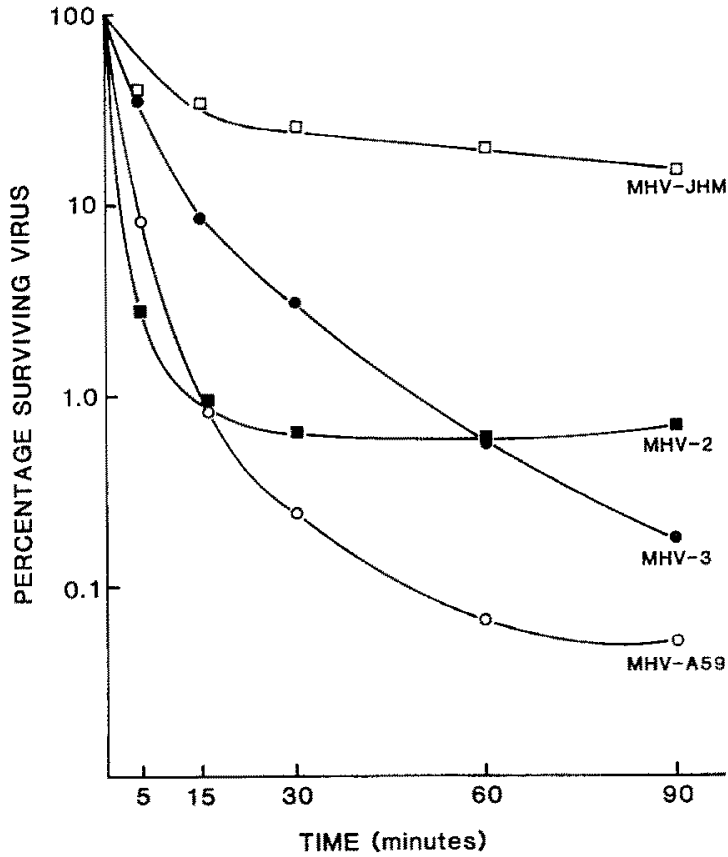

Fig. $1 d$ 
The antiserum prepared by immunization with $M H V-3$ exhibited interesting results in the kinetic neutralization test (Fig. 1 c). As expected from the reciprocal test the antiserum showed little or no ability to neutralize MHV-JHM. In contrast, this antiserum neutralized MHV-2 faster than the homologous virus, MHV-3, even though the reciprocal test showed little or no neutralization of MHV-3 by anti-MHV-2 antiserum. In addition, the antiserum was not able to distinguish between MHV 3 and MHV-A 59.

Antiserum to MHV-A59 was tested for its ability to distinguish the four strains of MHV (Fig. 1d). As with anti-MHV-2 and anti-MHV-3, this antiserum was also unable to neutralize MHV-JHM. The reaction with MHV-2, however, showed an initial neutralization rate that exceeded the rate with the homologous virus and then little or no subsequent neutralization. It was therefore possible that the MHV-2 pool contained two populations that could be distinguished by this antibody population but not by the anti-MHV-2 serum. A similar result was suggested by the reaction of anti-MHV-3 but the reaction with anti-MHV-A 59 was more distinct. To test the possibility that the MHV-2 population contained two groups with antigenically different major envelope glycoproteins, the MHV-2 population surviving after 90 minutes neutralization with antiserum to MHV-A59 was repropagated in DBT cells. This virus was then tested by kinetic neutralization with antiserum to $\mathrm{MHV}-\mathrm{A} 59$. The neutralization kinetics were identical to that of the parent virus, thus indicating that the apparent biphasic neutralization of MHV-2 by antiserum to MHV-A59 was a property of the antibody population and not the virus (data not shown). The anti-MHV-A59 antibody could differentiate between MHV-3 and MHV-A59, although even in these tests they are obviously closely related (Fig. 1d). Multiple kinetic neutralizations of MHV-A59 and MHV-3 using antiserum to MHV-A59 could distinguish between these two strains indicating that they are closely related but distinguishable by this technique (data not shown).

\section{Discussion}

MHV strains isolated from laboratory strains of mice cause a variety of diseases in their natural host (16). MHV-JHM is a neurotropic strain that primarily infects oligodendroglial cells in the central nervous system of mice $(12,13)$. MHV-A59 is relatively nonvirulent in mice (9), while MHV-3 and MHV-2 are extremely virulent causing fulminant hepatitis (16). However, these latter two viruses differ in that MHV-2 does not form giant cells in vitro, a property characteristic of all other MHV's (4). Although these isolates have been given different designations and treated as separate strains, there have been few attempts to define the antigenic relationships among these viruses or to conclusively prove that these isolates are antigenically distinct from each other. There have been recent reports of antigenic relationships among MHV strains that have used plaque reduction as a measure of antigenic relatedness $(3,14,15)$. A careful consideration of the data in these reports as well as the data in Table 1 leads to the conclusion that MHV strains are all antigenically related; however, the interrelationships among the strains vary in each of the three studies, probably reflecting differences in the antisera and the use of MHV strains with different passage histories. 
To understand more clearly the antigenic relatedness of the four MHV isolates with differing pathological and biological properties, the neutralization kinetics of four strains were examined. The individual antiserum to MHV-JHM and MHV-2 clearly showed that these viruses were distinct strains of MHV and that these antisera each exhibited little cross reactivity with the other strains tested. This contrasted with the present investigation (Table 1) and that of others showing that these viruses were closely related to other MHV's by plaquereduction neutralization $(3,14,15)$.

Antiserum to MHV-3 was not able to elearly distinguish MHV-3 from MHV. A59; however, the antiserum to MHV-A59 was able to distinguish between the two viruses. This result suggests that the major envelope glycoprotein, which has recently been shown to be the site of attachment for neutralizing antibody is highly conserved (1). This is in agreement with oligonucleotide fingerprints of MHV-3 and MHV-A59 which failed to show any difference in the gene encoding of this protein (8). Both antiserum to MHV-A59 and MHV-3, neutralized MHV-2 at a faster rate than either of the homologous viruses. The possibility that there were two populations in the MHV-2 pool was ruled out by retesting the survivors. Although no clear explanation is available, it is possible that the immunization of the $\mathrm{C} 57 \mathrm{BL} / 6 \mathrm{~J}$ mice elicited a population of heteroclitic antibodies. These antibodies, which are frequently elicited in $\mathrm{H}-2^{\mathrm{b}}$ mice, have a higher affinity for a heterologous antigen than for the specific immunogen (5).

Kinetic neutralization of murine coronaviruses appears to be a more sensitive method of detecting antigenic relationships than plaque reduction neutralization. Since varied disease syndromes are induced by MHV which induces different diseases depending on the route of inoculation, dose of virus, the age and genetic background of the host, it has become important to determine if the MHV isolates designated as strains are truly different viruses. This information will facilitate studies designed to understand the molecular basis of the diverse acute, chronic, and latent pathogenic process induced by members of this virus group.

\section{Acknowledgments}

We wish to thank Mr. R. Mitchell and Ms. A. Young for editorial assistance. This work was supported in part by grants NS 15079 and NS 18147 from the National Institutes of Health. The data are from a thesis submitted by JCC in partial fullment of the requirements for a degree of Master of Science, California State University, Long Beach.

\section{References}

1. Collins, A. R., Knobler, R. L., Poweld, H. R., Buchmeier, M. J. : Monoclonal antibodies to murine hepatitis virus.4 (Strain JHM) define the viral glycoprotein responsible for attachment and cell-cell fusion. Virology 119, 358-371 (1982).

2. GLEDHILL, A. W., NIVEN, J. S. F.: Latent virus as exemplified by mouse hepatitis virus (MHV). Vet. Rev. Annot. 1, 82 -90 (1955).

3. Huerholzer, J. C., Broderson, J. R., MurPhy, F.: New strain of mouse hepatitis virus as the cause of lethal enteritis in infant mice. Infect. Immun. 24, 508-522 (1979).

4. Hrrano, N., Fujiwara, K., Hino, S., Matumoto, M.: Replication and plaque formation of mouse hepatitis virus (MHV-2) in mouse cell line DBT culture. Arch. Virol. 44, 298-302 (1974). 
5. Kardalainen, K, Makela, O.: A Mendelian idiotype is demonstrable in the heteroclitic anti-NP antibodies of the mouse. Eur. J. Immunol. 8, 105-112 (1978).

6. LaI, M. M. C., Stohlman, S. A.: The RNA of mouse hepatitis virus. J. Virol. 26, $236-242(1978)$.

7. LaI, M. M. C., Stohlman, S. A.: Comparative analysis of RNA genomes of mouse hepatitis viruses. J. Virol. 38, 661-670 (1981).

8. Lai, M. M. C., Brayton, P. R., Armen, R. C., Patron, C., Pugh, C., Stohtman, S. A.: Mouse hepatitis virus A59: mRNA structure and genetic localization of the sequence divergence from hepatotropic strain MHV -3. J. Virol. 39, 823-834 (1981).

9. RoBB, J., Bond, C. W.: Pathogenic murine coronaviruses. I. Characterization of biological behavior in vitro and virus-specific intracellular RNA of strongly nourotropic JHM and weakly neurotropic A59 viruses. Virology 94, 352-370 (1979).

10. Siddeld, S., Wege, H., Ter Meulen, V.: The structure and replication of coronaviruses. Curr. Topies Microbiol. Immunol. 99, $131-163$ (1982).

11. Stohlman, S. A., Eylar, O. R., Wisseman, C. L.: Dengue viral antigens in host cell membranes. Acta Virol. 22, 31-36 (1978).

12. Stohlman, S. A., Freuinger, J. A., Weiner, L. P.: Resistance to fatal central nervous system disease by mouse hepatitis virus, strain JHM. II. Adherent cell mediated protection. J. Immunol. 124, 1733-1739 (1980).

13. Stohtman, S. A., Weiner, L. P.: Chronic central nervous system demyelination in mice after JHM virus infection. Neurol. 31, 38 44 (1981).

14. Tarechi, F., Marino, S., Fujiwara, K.: Antigenic differentiation of mouse hepatitis virus by neutralization test. Microbiol. Immunol. 26, 741-745 (1982).

15. Wege, H., Stepranson, R., Koga, M., Weqe, H., ter Meulen, V.: Genetic variation of neutropic and non-neurotropic murine coronaviruses. J. gen. Virol. $\mathbf{5 4}$, $67-74(1981)$.

16. Weat, H., StDdfxx, S., TER Meuten, V.: The biology and pathogenesis of coronaviruses. Curr. Topics Microbiol. Immunol. 99, 165-200 (1982).

Authors' address: Dr. S. A. STohtmar, MCH 142, 2025 Zonal Avenue, Los Angeles, CA 90033, U.S.A. 